\title{
QUEEN'S
UNIVERSITY
BELFAST
}

\section{Adjustment to hand injury Cross sectional survey exploring adjustment in relation to illness perceptions and coping strategies}

Turkington, C., Dempster, M., \& Maguire, J. (2017). Adjustment to hand injury Cross sectional survey exploring adjustment in relation to illness perceptions and coping strategies. Journal of Hand Therapy. https://doi.org/10.1016/j.jht.2017.05.021

Published in:

Journal of Hand Therapy

Document Version:

Peer reviewed version

Queen's University Belfast - Research Portal:

Link to publication record in Queen's University Belfast Research Portal

Publisher rights

(c) 2017 Hanley \& Belfus, an imprint of Elsevier Inc. All rights reserved.

This manuscript is distributed under a Creative Commons Attribution-NonCommercial-NoDerivs License

(https://creativecommons.org/licenses/by-nc-nd/4.0/), which permits distribution and reproduction for non-commercial purposes, provided the author and source are cited.

\section{General rights}

Copyright for the publications made accessible via the Queen's University Belfast Research Portal is retained by the author(s) and / or other copyright owners and it is a condition of accessing these publications that users recognise and abide by the legal requirements associated with these rights.

Take down policy

The Research Portal is Queen's institutional repository that provides access to Queen's research output. Every effort has been made to ensure that content in the Research Portal does not infringe any person's rights, or applicable UK laws. If you discover content in the Research Portal that you believe breaches copyright or violates any law, please contact openaccess@qub.ac.uk. 


\title{
Adjustment To Hand Injury: cross sectional survey exploring adjustment in relation to illness perceptions and coping strategies
}

\begin{abstract}
:
Introduction: Hand injuries are highly prevalent and the impact they have on physical, emotional, and functional adjustment is well recognised. Increasingly, adjustment to health conditions including hand injuries is being understood in terms of psychological variables.
\end{abstract}

Aim: To examine the role of illness beliefs and coping strategies in adjustment to hand injury. Adjustment was considered from a complete perspective including quality of life and functional ability as well as mood and trauma symptoms.

Method: Cross-sectional survey whereby consecutive patients $(n=65)$ attending the Regional Plastic Surgery Service with hand injuries were invited to complete a questionnaire assessing illness perceptions, coping strategies, quality of life, hand functioning, depression and trauma symptoms. Data were analysed in SPSS by correlation and then hierarchical regression analysis.

Results: Illness perceptions and coping strategies were significantly related to the adjustment outcomes (hand functioning, quality of life, depression and trauma symptoms). Specifically, poorer adjustment was associated with more negative illness beliefs ( $r=0.31$ to 0.47 ); greater use of denial ( $r=0.24$ to 0.53 ) and avoidance based ( $r=0.41$ to 0.64$)$ coping strategies.

Conclusions: Illness beliefs and coping play an important role in adjustment following hand injury. Adjustment is multifaceted with a need to consider physical and emotional functioning. More optimistic beliefs and adaptive coping styles are associated with improved adjustment. The role of psychological variables in optimising adjustment is an important consideration for the design of psychological interventions, but since this study was cross-sectional and cannot assume directional effects, future longitudinal studies are needed.

Key words: common sense model, hand injury, adjustment, illness beliefs

\subsection{Introduction}

Hand Injury is one of the most common injuries seen within a plastic surgery setting ${ }^{1-3}$ and one which has the potential to have a significant impact on physical, psychological, and functional abilities. ${ }^{4}$ Hand injuries typically result from unexpected and traumatic events that 
occur in a work or home environment. ${ }^{5}$ A range of studies have documented the impact a hand injury can have on body image, psychosocial difficulties, employment and relationships, as well as mood. ${ }^{6-9}$ Given the wide ranging impact a hand injury can have on an individual, developing a greater understanding of the factors that may help to promote adjustment in terms of biological, psychological, and social adjustment would be beneficial. The majority of studies conducted with hand injuries have looked at maximising physical recovery and adjustment in terms of medical or occupational therapy procedures. ${ }^{10-15}$ However less is known about the other aspects of adjustment, namely the role of psychological variables. This is an important element to consider given not only the active role each patient plays in their own recovery journey, ${ }^{4}$ but also because psychological adjustment plays a key role in how an individual copes with the social, financial, and recreational challenges typically faced by those with a hand injury. $5,7,16$

In trying to understand what influences or predicts who will experience difficulties with adaptation to this type of injury, previous studies have explored a range of variables including illness perceptions and mental health symptoms such as depression and trauma. 5,16,17 To date there is a recognition that each of these elements are important, however the research is still at early stages and no firm conclusions have yet been drawn.

Within the clinical health psychology literature, Leventhal's Common Sense Model of Illness Representations (CSM) ${ }^{18}$ is widely recognised as a robust model of adjustment ${ }^{19}$ that has been utilised in research with conditions such as Irritable Bowel Syndrome, ${ }^{20}$ Addison's Disease, ${ }^{21}$ Huntington's Disease,${ }^{22}$ cancer ${ }^{23}$, pain ${ }^{24}$ and general traumatic injury. ${ }^{25}$ The CSM proposes that individuals understand their condition in terms of the information available to them; this pool of information often includes pre-existing beliefs about the nature of their illness or injury for example from knowing others who have had the condition or through media representations of it. This initial understanding, or illness representation, informs their cognitive and emotional reactions to their diagnosis as well as determining their choice of coping style, for example seeking support or engaging with prescribed treatment plans. The CSM proposes that the individual reviews or appraises their situation which may lead to an adaptation of their coping style or a shift in how they understand their condition. As new information becomes available, either through contact with professionals or other patients, or via their first-hand experience living with their condition, this is assimilated into their illness representation and may lead to a modification of their cognitive and emotional beliefs.

As the individual incorporates new information into this system it changes how they perceive and thus how they react and adjust to it. Where their beliefs match the reality of their 
situation this may help with adjustment for example positive motivation to engage in rehabilitation programs or to actively engage in positive coping strategies. In the short term, there is also evidence that unrealistically positive beliefs may be helpful in facilitating coping and adjustment. ${ }^{26,27}$ However, where new information is not integrated into the individual's belief system over the course of the recovery journey, unhelpful or unrealistic beliefs may arise that create difficulties with the adjustment process. Chan et al. ${ }^{4}$ concluded that at least during the acute stages of recovery, patients' illness beliefs do not appear to be related to the severity of their injury. They suggested that this may be due to overly optimistic expectations which are likely to alter during the course of their recovery and may influence their engagement with rehabilitation therapy as well as their emotional adjustment. Indeed, Gustafsson, Windahl and Blomberg ${ }^{5}$ observed in their longitudinal study that a subset of patients did not report any psychological distress initially and then went on to develop increasing difficulties over the coming months and years. These patients ultimately were reporting the highest levels of psychological distress at the 10 year follow up.

It has been estimated that nearly everyone who sustains a hand injury will experience some symptoms of anxiety, depression, trauma, or adjustment difficulties, ${ }^{16}$ with some studies reporting that up to $90 \%$ of hand injury patients report intrusive symptoms during the immediate weeks following an accident resulting in the injury. ${ }^{28}$ It has also consistently been reported within the literature that psychological difficulties decrease during the acute phase of recovery, however after the 3 month mark they tend to remain stable $5,29,30$ and thus provide an indication of those individuals who are most likely to benefit from additional support. Expanding on this, Williams et al. ${ }^{17}$ proposed that depression and trauma symptoms had a significant impact on an individual's adjustment to their hand injury. Using the SF-36 31 as a measure of functional health status and adjustment, they concluded that posttraumatic stress disorder and depression had a detrimental impact on an individual's adjustment to hand injury, particularly when they were comorbid; a conclusion that is supported in other papers. ${ }^{32}$

The current evidence base for understanding an individual's adjustment to their hand injury supports the role of a range of variables and factors, including their illness beliefs, mood and trauma symptoms, coping style employed, and how in tune these are with the functional severity of the injury. However, while previous studies have identified and discussed these factors, none have done so in an inclusive manner. It is possible to say these factors are important, but their comparative role in this adjustment process has not been examined. The aim of this study then was to use the CSM as the basis from which to investigate the role of illness perceptions on adjustment to hand injury, where adjustment is understood in terms of emotional adjustment, coping, functional outcome, and quality of life. 


\subsection{Method}

\subsection{Study design}

All patients attending the plastic surgery clinic with hand injuries between May 2015 and March 2016 were invited to take part via a postal survey; research packs were also available on the ward and 2 participants (3\%) accessed them via this method. Each patient was invited to complete a set of 6 questionnaires. If their hand injury prevented this then they could request an alternative method (phone or email). Participants were excluded if they did not have a level of functional English. No-one requested additional support with completion of the questionnaires and 1 participant requested an electronic version and returned it via email.

Ethical approval was obtained prior to data collection commencing.

In total 62 participants were recruited to the study. A sample size of 62 is sufficient to detect an R-squared value of at least 0.3 in a regression with up to 17 predictors, with $80 \%$ power, using an alpha value of $0.05^{66}$. As all of the final regression models exceeded an R-value of 0.3 , the regression analyses can be considered to be adequately powered.

\subsection{Demographics}

Consent was sought to access participants' medical records to obtain information about the participant's age, gender, marital status, time since injury (months), and if their injury was to their dominant or non-dominant hand.

\subsection{Measures}

The Revised IIIness Perception Questionnaire (IPQ-R ${ }^{33}$ is widely used within health and illness research to measure and identify illness perceptions ${ }^{34}$. It was derived from the CSM and as such is felt to be the most suitable measure to address illness perceptions within this study. The IPQ-R consists of 8 subscales with additional questions about the participant's perceived cause of their condition. In this study an adapted version of the IPQ-R was used where the term 'illness' was replaced with 'hand injury'. In order to minimise the number of items being included only the 7 subscales directly asking about illness beliefs were included. The 7 subscales constitute 38 statements rated on a 5 point Likert scale (strongly disagree to strongly agree). Moss-Morris et al. ${ }^{33}$ reported that all 7 subscales have good internal consistency (Cronbach Alpha 0.79 to 0.89 ) and good test-retest reliability (with all correlations between the two time points over 0.5 ). This measure has been used within the hand injury literature and has been validated for use with this population. ${ }^{4}$ 
The Revised Impact of Event Scale (IES-R) ${ }^{35}$ was designed to build upon the original IES ${ }^{36}$ and it has an additional subscale for Hyper-arousal to better represent the diagnostic criteria for a trauma diagnosis. ${ }^{37}$ The IES-R consists of 22 items which form 3 subscales; Intrusion, Avoidance, and Hyper-arousal. Each item is rated on a 0 (not at all) to 4 (extremely) Likert scale. The IES-R has been reported to have high internal consistency (Cronbach's alpha: Intrusion - 0.87-0.94; Avoidance - 0.84-0.87; Hyper-arousal -0.79-0.91), as well as a testretest reliability of $0.89-0.94 .^{37}$

The Patient Health Questionnaire 9 (PHQ 9) ${ }^{38}$ is a standardised outcome measure for identifying a patient's mood and symptoms of depression. It has been widely used within physical health and primary care settings and is generally considered to be a reliable and valid measure of mood, specifically depression, with good internal consistency and testretest results. ${ }^{9,38,39}$ The PHQ-9 consists of 9 items designed to map onto the diagnostic criteria for depression in the Diagnostic and Statistical Manual of Mental Disorders (DSMIV). ${ }^{40}$ Each item is scored on a Likert scale from 0 to 3 ( $0=$ not at all, 1=several days, 2=more than half the days, 3=nearly every day) to indicate how much the individual has been bothered by each symptom in the past 2 weeks. Summed scored can range from 0 to 27 , with scores greater than 10 indicating the presence of depression. ${ }^{38}$

The Brief COPE ${ }^{41}$ was chosen as a measure of participants' coping styles. The Brief COPE is a self-report measure consisting of 14 subscales totalling 28 items which are scored on a 4 point Likert scale where a higher score indicates greater engagement with that coping style. It has been reported to have good reliability and validity. ${ }^{42,43}$ Carver $^{41}$ reported Cronbach's alpha values for the subscales ranging from 0.25 to 1.0 , with 10 of the subscales indicating values above 0.6 .

The QuickDASH ${ }^{44}$ is a measure of functional ability in an individuals' arm, shoulder or hand and is used as a measure of functional recovery and adaptation within the hand injury literature. ${ }^{9}$ The QuickDASH consists of 11 items; 8 addressing function and 3 addressing symptoms such as pain. As a brief version of the well-established DASH measure, ${ }^{45}$ Angst et al.'s ${ }^{46}$ paper reviewing both measures, importantly found that both had comparable testretest reliability. Similarly they reported excellent internal consistency with Cronbach's alpha values of 0.97 for the DASH and 0.92 for the QuickDASH. The QuickDASH also functions as a measure of a participant's current perception of pain. While this forms part of the overall QuickDASH score, it can also be considered as an independent score and therefore serve as a pain measurement.

The Medical Outcome Study Short Form 36 Health Survey (SF-36) ${ }^{37}$ is one of the most commonly used measures of health related quality of life within health care research, 
including hand injury populations. ${ }^{17,47-51}$ It has been reported as a valid measure that is responsive to changes in health status over time..$^{49}$ It consists of 8 domains which are converted into 2 component scores: Physical Component Scores (PCS) and Mental Component Scores (MCS); a higher score indicates better functioning in both components. The internal consistency has been reported as greater than 0.7 across all domains. ${ }^{49}$ Failde and Ramos $^{49}$ also support the instrument's construct validity.

\subsection{Analysis}

All data was entered into SPSS version 22. Cluster analysis was performed with the IPQ-R data to identify participants who held similar illness beliefs. Milligan's two stage method was used. ${ }^{52,53}$ It is an ideal method for illness perception research ${ }^{54,55}$ as it enables the results from the IPQ-R to be condensed to enable greater clarity within the analysis and clusters of those who respond similarly to be identified. A hierarchical cluster analysis (Ward's clustering method) was run to identify the number of clusters as determined by squared Eucildean distance. By consulting the dendrogram and agglomeration schedule to clarify the presence of any valid clusters, two clusters were identified which indicated there were two types of responders within this data set, based on their IPQ-R answers; description of these clusters is summarised in Table 1.

Correlational analysis was then conducted to identify relationships between the variables and to inform subsequent hierarchical linear regression models. An absolute correlation of $r$ $=0.2$ or greater (which was significant at the 0.05 level) was considered large enough to indicate a potentially meaningful relationship between the variables and therefore included in the subsequent regressions. Although a correlation coefficient of 0.2 is considered small, independent variables can have larger relationships with the outcome variable in the context of a regression, so a small correlation was chosen to ensure that no potentially meaningful findings were missed in the regression analyses.

\subsection{Results}

\subsection{Demographics}

Of the 65 patients recruited, $60 \%(n=39)$ were male and the mean age was 54 years with a range from 18 to 86 years. Thirty five (54\%) were married and $38(58 \%)$ sustained an injury to their dominant hand. Two participants (3\%) had sustained their injury in the past 3 months, $45(69 \%)$ had sustained their injury between 3 and 12 months previously, and 18 $(28 \%)$ had sustained their injury more than 12 months previously. 


\subsection{Perceptions of Hand Injury}

As described above and illustrated in Table 1, the results for the IPQ-R were summarised using cluster analysis to produce two clusters; 63 participants completed the full IPQ-R.

Cluster 1 contains 30 participants (48\%) who believe that their injury will be longer lasting, have recurrent difficulties, and have more negative consequences. They report lower levels of personal control and have moderate belief in the ability of their treatments to manage their injury. They report similar levels of understanding of their injury to cluster 2 , however they report significantly higher negative emotional responses to their injury. In contrast then, cluster 2 contained 33 participants (52\%) and this cluster was found to share illness beliefs relating to more positive outcomes such as their injury having less negative consequences and lasting a shorter more acute period of time. They felt both their surgery and their own behaviour would have a positive influence on their recovery journey, and they reported less negative emotional reactions to their injury.

\section{Table 1}

Illness Perception Clusters

\begin{tabular}{|c|c|}
\hline & Mean (SD) \\
\hline \multicolumn{2}{|l|}{ Timeline (/30) } \\
\hline Cluster 1 & $21.6(2.8)$ \\
\hline \multicolumn{2}{|l|}{ Consequences $(/ 30)$} \\
\hline Cluster 1 & $17.8(3.1)$ \\
\hline Cluster 2 & $12.2(3.3)$ \\
\hline \multicolumn{2}{|l|}{ Personal Control (/30) } \\
\hline Cluster 1 & $14.9(3.8)$ \\
\hline Cluster 2 & 19.9 (3.5) \\
\hline \multicolumn{2}{|l|}{ Treatment Control (/25) } \\
\hline $\begin{array}{r}\text { Cluster } 1 \\
\end{array}$ & $14.2(2.6)$ \\
\hline Cluster 2 & $15.5(2.1)$ \\
\hline \multicolumn{2}{|l|}{ Illness Coherence (/25) } \\
\hline $\begin{array}{r}\text { Cluster } 1 \\
\text { C }\end{array}$ & $12.9(4.4)$ \\
\hline Cluster 2 & $10.9(2.7)$ \\
\hline \multicolumn{2}{|l|}{ Timeline Cyclical (/20) } \\
\hline Cluster 1 & $10.2(3.2)$ \\
\hline Cluster 2 & $7.7(4.0)$ \\
\hline \multicolumn{2}{|l|}{ Emotional Responses } \\
\hline $\begin{array}{l}\text { Cluster } 1 \\
\text { Cluster } 2\end{array}$ & $11.9(2.4)$ \\
\hline
\end{tabular}

\subsection{Coping Styles}

Fifty-two participants (80\%) stated never using 'denial' in terms of managing their injury and conversely the highest endorsed coping style was 'acceptance' with 60 participants (92\%) stating they use this to some degree and over a third stated that they use this coping style a lot of the time. Results are summarised in Table 2. 
Table 2

Summary of Brief COPE scores

\begin{tabular}{|l|c|c|}
\hline COPE style & Mean (SD) & Possible Range \\
\hline Self-Distraction & $3.51(1.89)$ & $2-8$ \\
\hline Active Coping & $4.17(2.23)$ & $2-8$ \\
\hline Denial & $2.58(1.36)$ & $2-8$ \\
\hline Substance Use & $2.37(1.08)$ & $2-8$ \\
\hline Emotional Support & $3.80(2.01)$ & $2-8$ \\
\hline Instrumental Support & $3.15(1.46)$ & $2-8$ \\
\hline Behavioural Disengagement & $2.46(1.08)$ & $2-8$ \\
\hline Venting & $2.75(1.19)$ & $2-7$ \\
\hline Positive Reframing & $3.63(1.79)$ & $2-8$ \\
\hline Planning & $4.25(2.17)$ & $2-8$ \\
\hline Humour & $4.12(1.97)$ & $2-8$ \\
\hline Acceptance & $5.85(2.07)$ & $2-8$ \\
\hline Religion & $3.03(1.73)$ & $2-8$ \\
\hline Self-Blame & $3.29(1.77)$ & $2-8$ \\
\hline
\end{tabular}

\subsection{Adjustment Outcomes}

Adjustment was measured in terms of functional ability, quality of life, depression symptoms, and trauma symptoms; the results of these measures are summarised in Table 3 . In relation to physical functioning (QuickDASH) a higher score indicates a greater level of self-reported impairment. Only $2(3.1 \%)$ participants reported no impairment. A higher score on the IES-R similarly indicates higher level of self-reported trauma symptoms; $11(17 \%)$ participants rated themselves within the clinical range with $9(14 \%)$ rating their trauma symptoms in the extremely high range. For the PHQ-9 scale a higher score indicates more self-reported depression symptoms; the majority $(61 \%)$ rated themselves as having none or minimal symptoms with 10 participants $(16 \%)$ indicating they are experiencing moderate to severe symptoms of depression. For quality of life (SF-36) a higher score indicates better functioning on each health state.

Table 3

Summary of outcome variables

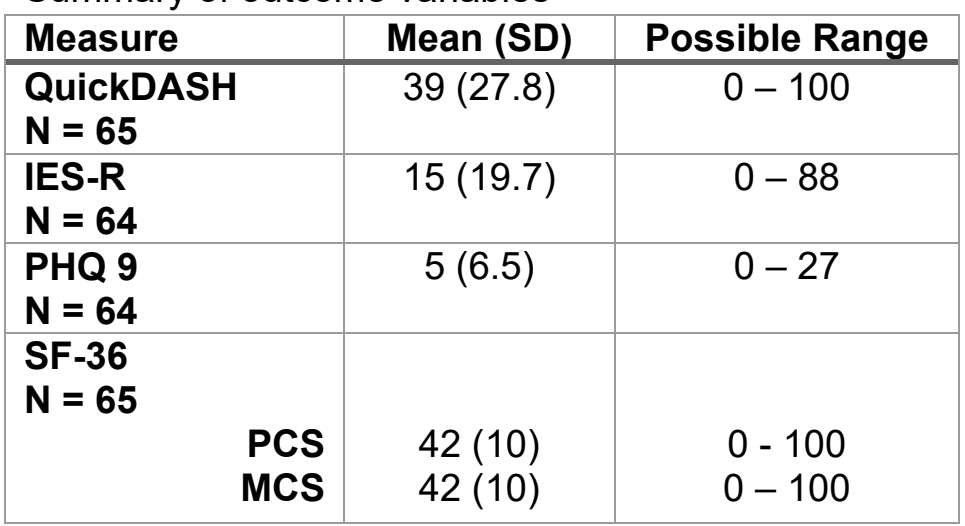




\subsection{Correlations}

The relationships between all potential covariates and all outcome variables were assessed using correlation coefficients. Covariates with an absolute correlation of $r=0.2$ or greater with an outcome variable were included in the subsequent regressions, summarised in Table 4.

Table 4

Summary of correlations

\begin{tabular}{|c|c|c|c|c|c|}
\hline & $\begin{array}{l}\text { PHQ9tot } \\
\text { al }\end{array}$ & IESRtotal & $\begin{array}{l}\text { DASH } \\
\text { total }\end{array}$ & MCS & PCS \\
\hline $\begin{array}{l}\text { Illness perception } \\
\text { Cluster }\end{array}$ & $-.47^{* *}$ & $-.46^{* *}$ & $-.31^{*}$ & $.42^{* *}$ & $.34^{* \star}$ \\
\hline Age & $-.34^{* *}$ & $-.48^{* *}$ & $-.25^{*}$ & $.28^{*}$ & .15 \\
\hline Gender & -.10 & -.15 & -.06 & .05 & .09 \\
\hline Married & $.29^{*}$ & $.37^{* *}$ & $.32^{*}$ & -.23 & $-.31^{*}$ \\
\hline Dominant & -.01 & -.10 & .18 & -.11 & -.20 \\
\hline months since & -.03 & .05 & $-.27^{*}$ & .08 & .21 \\
\hline self distraction & $.48^{* *}$ & $.52^{* *}$ & $.26^{*}$ & $-.42^{* *}$ & $-.35^{* *}$ \\
\hline active coping & .12 & $.37^{* *}$ & $.37^{* *}$ & -.15 & -.18 \\
\hline Denial & $.53^{* *}$ & $.49^{* *}$ & $.29^{*}$ & -.24 & $-.32^{*}$ \\
\hline substance use & .22 & .21 & .05 & $-.28^{*}$ & -.19 \\
\hline emotional support & $.39^{* *}$ & $.48^{* *}$ & $.53^{* *}$ & $-.42^{* *}$ & $-.37^{* *}$ \\
\hline instrumental support & .23 & $.35^{* *}$ & $.31^{*}$ & $-.31^{*}$ & $-.27^{*}$ \\
\hline $\begin{array}{l}\text { behavioural } \\
\text { disengagement }\end{array}$ & $.33^{* *}$ & $.29^{*}$ & .20 & $-.29^{*}$ & $-.30^{*}$ \\
\hline Venting & $.47^{* *}$ & $.64^{* *}$ & $.41^{* *}$ & $-.53^{* *}$ & $-.45^{* *}$ \\
\hline positive reframing & .19 & $.31^{*}$ & $.28^{*}$ & -.17 & -.18 \\
\hline Planning & .25 & $.40^{* *}$ & $.46^{* *}$ & $-.33^{* *}$ & $-.42^{* *}$ \\
\hline Humour & -.11 & .21 & -.06 & .06 & .06 \\
\hline Acceptance & .002 & .20 & .12 & -.06 & -.09 \\
\hline Religion & -.14 & -.07 & .02 & .16 & .02 \\
\hline self-blame & $.36^{* *}$ & $.40^{* *}$ & .21 & $-.29^{*}$ & $-.29^{*}$ \\
\hline
\end{tabular}

\subsection{Regression}

Hierarchical linear regression was carried out to investigate which independent variables explain the variance of five criterion variables: quality of life (PCS and MCS), trauma, depression, and functional ability. Demographic variables were entered in the first block, followed by the illness perceptions clusters and coping variables in the second block. The variable with the lowest standardised regression coefficient was then eliminated and the 
model run again. This iterative process was continued until the adjusted R-squared value was maximised. Only the final regression model is presented for each outcome variable (see Table 4). All assumptions of regression were checked and were met. During this process, one case was deemed a high leverage point (using Mahalanobis' Distance) for all regressions and was, therefore, omitted from the analyses.

\subsection{Quality of Life}

In relation to the SF-36 Physical Composite Score (PCS), demographic and medical variables explained $2.4 \%$ of the variance, with the psychological variables explaining an additional $28 \%$. Those individuals reporting better PCS used less venting as a coping strategy and were more likely to have a dominant hand injury.

For the Mental Composite Score (MCS) regression, all explained variance was attributable to psychological variables. Those participants reporting better MCS used less venting as a coping strategy.

\subsection{Depression}

No demographic variables were included in the final regression model with depression as the outcome. Psychological variables explained $56.3 \%$ of the variance in depression. Participants reporting higher rates of depression symptoms also reported increased use of denial and less use of instrumental support coping strategies. In terms of their illness perceptions they identified more strongly with cluster 1.

\subsection{Trauma}

Demographic and medical variables explained $26 \%$ of the variance in trauma symptoms, with psychological variables explaining an additional $41.1 \%$. More severe trauma symptoms were reported by younger participants who reported more use of self-blame, denial, seeking emotional support, self-distraction, and venting as coping styles while using less instrumental support, positive reframing and behavioural disengagement.

\subsection{Hand functioning}

Almost $17 \%$ of the variance in hand functioning was explained by demographic and medical variables, with psychological variables explaining an additional $24.8 \%$. Higher subjective severity ratings were predicted by less time having passed since the injury. These participants also reported greater use of emotional support as a coping strategy. 
Table 4

Summary of regression models

\begin{tabular}{|c|c|c|c|c|}
\hline $\begin{array}{l}\text { Regression } \\
\text { Model }\end{array}$ & $\begin{array}{c}R^{2}(\%) \\
\text { block } 1\end{array}$ & $\begin{array}{c}R^{2}(\%) \\
\text { block } 2\end{array}$ & $\begin{array}{l}\text { Predictor } \\
\text { Variable }\end{array}$ & $\begin{array}{c}\text { Standardised } \\
\text { Regression } \\
\text { Coefficient }\end{array}$ \\
\hline \multirow{5}{*}{$\begin{array}{l}\text { SF-36, PCS } \\
F(5,56)= \\
6.33, \\
p<.001\end{array}$} & \multirow{5}{*}{$\begin{array}{l}0.02 \\
(2.4 \%)\end{array}$} & \multirow{5}{*}{$\begin{array}{l}0.30 \\
(30.4 \%)\end{array}$} & Dominant & $-0.30^{*}$ \\
\hline & & & Cluster & 0.17 \\
\hline & & & Self-distraction & -0.17 \\
\hline & & & Denial & -0.16 \\
\hline & & & Venting & $-0.30^{*}$ \\
\hline \multirow{3}{*}{$\begin{array}{l}\text { SF-36, MCS } \\
F(3,58)= \\
11.71, \\
p<.001\end{array}$} & \multirow{3}{*}{$\begin{array}{l}\text { None } \\
\text { included }\end{array}$} & \multirow{3}{*}{$\begin{array}{l}0.35 \\
(34.5 \%)\end{array}$} & Cluster & 0.22 \\
\hline & & & Self-distraction & -0.20 \\
\hline & & & Venting & $-0.38^{* *}$ \\
\hline \multirow{6}{*}{$\begin{array}{l}\text { PHQ-9 } \\
\text { F }(6,55) \\
=11.796, \\
p<.001\end{array}$} & \multirow[t]{6}{*}{$\begin{array}{l}\text { None } \\
\text { included }\end{array}$} & \multirow[t]{6}{*}{$\begin{array}{l}0.56 \\
(56.3 \%)\end{array}$} & Cluster & $-0.24^{*}$ \\
\hline & & & Self-distraction & 0.12 \\
\hline & & & Denial & $0.46^{* *}$ \\
\hline & & & $\begin{array}{l}\text { Emotional } \\
\text { support }\end{array}$ & 0.23 \\
\hline & & & Venting & 0.20 \\
\hline & & & $\begin{array}{l}\text { Instrumental } \\
\text { support }\end{array}$ & $-0.26^{*}$ \\
\hline \multirow{11}{*}{$\begin{array}{l}\text { IES-R } \\
F(11,49)= \\
12.11 \\
p<.001\end{array}$} & \multirow{11}{*}{$\begin{array}{l}0.26 \\
(26.0 \%)\end{array}$} & \multirow{11}{*}{$\begin{array}{l}0.67 \\
(67.1 \%)\end{array}$} & Age & $-0.20^{*}$ \\
\hline & & & Married & 0.17 \\
\hline & & & Cluster & -0.14 \\
\hline & & & Self-distraction & $0.24^{*}$ \\
\hline & & & Denial & $0.30^{* *}$ \\
\hline & & & $\begin{array}{l}\text { Emotional } \\
\text { support }\end{array}$ & $0.21^{*}$ \\
\hline & & & Venting & $0.41^{* *}$ \\
\hline & & & $\begin{array}{l}\text { Behavioural } \\
\text { disengagement }\end{array}$ & $-0.22^{*}$ \\
\hline & & & $\begin{array}{l}\text { Positive } \\
\text { reframing }\end{array}$ & $-0.26^{*}$ \\
\hline & & & Self-blame & 0.19 \\
\hline & & & $\begin{array}{l}\text { Instrumental } \\
\text { support }\end{array}$ & -0.16 \\
\hline \multirow{6}{*}{$\begin{array}{l}\text { QuickDASH } \\
F(6,55)= \\
8.21, \\
p<.001\end{array}$} & \multirow{6}{*}{$\begin{array}{l}0.17 \\
(16.7 \%)\end{array}$} & \multirow{6}{*}{$\begin{array}{l}0.42 \\
(41.5 \%)\end{array}$} & Married & 0.18 \\
\hline & & & Months since & $-0.27^{*}$ \\
\hline & & & Cluster & -0.18 \\
\hline & & & $\begin{array}{l}\text { Emotional } \\
\text { support }\end{array}$ & $0.43^{* *}$ \\
\hline & & & $\begin{array}{l}\text { Instrumental } \\
\text { support }\end{array}$ & -0.16 \\
\hline & & & Planning & 0.23 \\
\hline
\end{tabular}




\subsection{Discussion}

This study sought to examine the role of illness perceptions and coping on adjustment to hand injury in terms of mood and trauma symptoms, quality of life and functional outcomes.

There is emerging evidence that the occurrence of both depression and trauma symptoms in individuals with hand injuries predicts poorer adjustment. ${ }^{17}$ In this study $14 \%$ met diagnostic criteria for depression and 16\% met diagnostic criteria for Post-Traumatic Stress Disorder (PTSD) according to the guidance for the measures used. ${ }^{35-38}$ This is somewhat lower than other studies in the area. ${ }^{17,32,67}$ This may suggest that due to the self-selecting nature of the study, those who were struggling the most following their injury did not opt into the study and the results are based on a group who are generally coping better than average. It may also suggest that, as $81 \%$ of the participants sustained their injury within the past 18 months, they may still be somewhat optimistic about their recovery and still engaged in recovery therapies. However, the consensus from the longitudinal studies conducted in relation to hand injuries is that the majority of individual's illness beliefs and depression or trauma symptoms remain stable from 3 months post injury. ${ }^{5,16,29}$ After 3 months it appears that the feedback loop of the CSM has achieved stability, whereby the new information about their injury has been incorporated into their belief systems and a stable pattern of coping has been identified.

It is also worth noting that a third reported at least mild depression symptoms and a fifth reported trauma symptoms that the measure describes as being of clinical concern. In terms of identifying those patients more likely to experience these difficulties and who may warrant closer observations or consideration of psychological intervention, the regressions reveal that younger people who express more negative beliefs about their injury (cluster 1) and who appear to be utilising coping strategies such as denial, avoidance or self-distraction, seeking more emotional support, and who have internalised a degree of self-blame in relation to their injury are more at risk of experiencing depression and trauma symptoms.

Poorer QOL was found to be associated with a venting coping style even after medical and demographic variables had been taken into consideration. A relationship between venting and poor QOL has been found for other conditions. ${ }^{68,69}$ Therefore, it could be that participants reporting greater difficulties with their physical and mental QOL, were consequently saying things to try and express their negative feelings, or it could be that using venting as a coping strategy has a negative impact on perceptions of QOL. The direction of the relationship cannot be discerned from the current data.

While it is perhaps less surprising that QOL, mood, and trauma outcomes are significantly associated with the psychological variables proposed by the CSM, it is striking that functional 
outcomes, including experience of pain, are also significantly associated with psychological variables. Interestingly $41.5 \%$ of the variability found in this measure was explained by the illness beliefs and coping styles where greater functioning impairments were related to, in particular, greater use of emotional support. Bot et al. ${ }^{9}$ reported that psychological variables were the greatest predictor of disability within their population and suggested that this was due to patients' self-efficacy and belief in their own ability to cope with and manage their hand injury. Chan et al. ${ }^{4}$ similarly found that within their hand injury population there was no correlation between the objective severity of the injury and the subjective severity nor the patient's illness perceptions.

The CSM suggests that the nature of the injury or illness may be less important than the individual's perception of it and their evaluation of their ability to cope with it. These results indicate that this may well be the case. It would be important, then, for future research to conduct longitudinal and qualitative studies to clarify this further.

\subsection{Clinical Implications and future research}

These results support previous studies and endorse the CSM as a framework from which to better understand and conceptualise a patient's adjustment to their hand injury. The model proposes that it is important to identify and optimise an individual's beliefs about their condition and subsequently enable them to employ the most helpful coping strategies to maximise their adjustment. If indeed this theory holds true, then it is possible that early intervention such as education and adjustment work may benefit individuals' longer term adjustment by optimising their perception of their injury and assisting them to develop helpful coping strategies.

This study identified that up to a third of patients may be experiencing difficulties in relation to depression and trauma, a figure that may actually be a conservative estimate based on the self-selecting nature of the study. Drawing on Williams et al. ${ }^{17}$ work this may suggest a significant proportion of the hand injury population are at increased risk for adjustment difficulties and may benefit from some early intervention. In terms of the direction of future research, intervention studies would be important to conduct to explore if psychoeducation and early intervention targeted at individuals who are reporting cluster 1 type illness beliefs and who are engaging in coping strategies such as avoidance and denial would aid in the adjustment process. Of particular note, qualitative studies would be of benefit to identify in depth processes of adjustment that the quantitative measure may be missing, and to aid in the interpretation of the their results.

Indeed, these results can help suggest what interventions may be of most benefit to this population. There is evidence that illness beliefs play a key role in the adjustment process 
and that negative beliefs are predictive of more depression and trauma symptoms. The nature of hand injuries is such that many people do experience life changing injuries and it is important for them to engage in the rehabilitation program to maximise functional recovery, although a full return to pre-injury functioning is often not possible. Psychological approaches such as Acceptance and Commitment Therapy (ACT $)^{57}$ are well placed to address situations where a full return to pre-injury functioning is impossible. ACT is becoming increasingly used within the chronic illness arena ${ }^{58-60}$ due to its focus on recognising and accepting the reality of the situation, and then learning to make choices that enable patients to live well and maximize their quality of life despite their difficulties. This approach would challenge patients who have the automotive tendency to engage in the coping strategies noted as predicting poorer adjustment namely avoidance and distraction. There is evidence for ACT to be effective when delivered in individual and in group formats, ${ }^{61-63}$ however in chronic conditions such as chronic pain, which is often experienced by those with a hand injury, ${ }^{32,64}$ group delivery is recommended. ${ }^{65}$ This delivery format may also provide the emotional support sought by those patients reporting higher levels of depression, trauma symptoms, and functional difficulties. To date, there is no research conducted specifically on the use of ACT with hand injuries, and very limited research examining the impact of any specific psychological interventions with this population. Therefore, there is a clear need for this to be explored given the rates of psychological difficulties reported by this population and the chronic nature of the injury that will continue to impact on their lives for many years to come.

\subsection{Limitations}

The major limitation of this study is that it was a cross-sectional study and no cause and effect can be determined. While it is possible that the psychological constructs we measured influenced recovery or perceptions of recovery, it is also possible that nature of the injury and recovery influenced psychological perceptions. Of note, we did not have access to participants' history in terms of premorbid mental health difficulties, or specifically any prior traumas or injuries. This would be a valuable consideration for future studies as it would aid better understanding of what outcomes are directly resultant from the injury or not. Possibly a hand injury presents greater adjustment difficulties to those patients with premorbid difficulties, in a cumulative effect. However, it may also be the case that adjustment to an injury is more challenging to those patients with no history of trauma as it perhaps shattered their illusion of safety and they have no previous experience with coping with adversity; this is an area poorly researched within the hand injury literature and as such should be expanded upon in future studies. 
Having a relatively small sample of self-selecting participants limits the stability of our regression models, and the generalizability of the results. In addition, it was noted that this sample reported lower rates of depression and trauma symptoms than did comparable studies suggesting that possibly the self-selecting nature of this study failed to capture those who are struggling the most. As such, these results need to be interpreted cautiously and seen within the context of the wider literature base. When considered within this context, these results sit well with previous findings, which suggest some degree of validity and reliability. The study population represents a good spread of ages, gender, and injury to a dominant hand which is felt to accurately reflect the clinical population at large.

As noted in related studies by Chan et al. ${ }^{4}$ and Bot et al ${ }^{9}$ there are additional variables that may be at play that were not accounted for in this study; namely objective severity of the injury, and self-efficacy. While this study combined a broad range of covariates and outcome variables, the process of adjustment remains a highly complex process and one which involves more psychological variables than were addressed here. This study serves to add to this knowledge base and highlights the significant role for considering greater psychological variables within the treatment of hand injuries, as well as highlighting the need for additional studies to be undertaken.

\subsection{Conclusions}

Previous studies in chronic conditions support the use of the CSM in providing a framework through which to understand adjustment. ${ }^{4,20-24,54,55}$ The literature on hand injuries focuses predominantly on functional outcomes and only a few studies have considered the role of illness beliefs. These few studies however suggest that psychological variables are important in this area. The results of this study also indicate that psychological variables play a very significant role in an individual's adjustment in terms of how they understand and think about their condition, how they feel about it, and how to seek to cope with it. These factors are more strongly related to good adjustment outcomes than demographic or medical factors.

These findings suggest that greater attention should be paid to psychological variables in the treatment of hand injury. Perhaps in terms of screening tools to identify those most at risk of poor adjustment, or routine provision of psychoeducation sessions or earlier referral for psychological support. What is clear, however, is that further good quality, longitudinal, and intervention based studies are required to further understanding in this area. 


\subsection{References}

1. Packer GJ, Shaheen MA. Patterns of hand fractures and dislocations in a district general hospital. J Hand Surg Eur. 1993:18:511-514.

2. Angermann P, Lohmann M. Injuries to the hand and wrist. A study of 50, 272 injuries. J Hand Surg Eur. 1993:18:642-644.

3. Hill C, Riaz M, Mozzam A, Brennan MD. A regional audit of hand wrist injuries. A study of 4873 injuries. J Hand Surg Eur. 1998:23:196-200.

4. Chan JCY, Ong JCY, Avalos G, Regan PJ, McCann J, Groarke AM, Kelly JL. Illness representations in patients with hand injury. J Plast Reconstr Aesthet Surg. 2009:62:927932.

5. Gustafsson M, Windahl J, Blomberg K. Ten years follow-up of trauma-related psychological distress in a cohort of patients with acute traumatic hand injury. Int J Orthop Trauma Nurs. 2012:16:128-135.

6. Rumsey N, Harcourt D. Body image and disfigurement: issues and interventions. Body Image. 2004:1:83-97.

7. Hannah SD. Psychological issues after a traumatic hand injury: facilitating adjustment. J Hand Ther. 2011:24(2):95-102.

8. Chan J, Spencer J. Adaptation to hand injury: an evolving experience. Am J Occup Ther. 2004:58(2):128-139.

9. Bot AGJ, Bossen JKJ, Mudgal CS, Jupiter JB, Ring D. Determinants of disability after fingertip injuries. Psychosomatics. 2014:55:371-380.

10. Meals C, Meals R. Hand fractures: a review of current treatment strategies. J Hand Surg Am. 2013:38(5):1021-1031.

11. Vaksvik T, Kjeken I, Holm I. Self-management strategies used by patients who are hypersensitive to cold following a hand injury. A prospective study with two years follow-up. J Hand Ther Am. 2015:28(1):46-52.

12. Kingston GA, Williams G, Gray MA, Judd J. Does a DVD improve compliance with home exercise programs for people who have sustained a traumatic hand injury? Results of a feasibility study. Disabil Rehabil Assist Technol. 2014:9(3):188-194. 
13. Shi Q, Sinden K, MacDermid JC, Walton D, Grewal R. A systematic review of prognostic factors for return to work following a work-related traumatic hand injury. J Hand Ther Am. 2014:27(1):55-62.

14. Roesler ML, Glendon AI, O'Callaghan FV. Recovering from traumatic occupational hand injury following surgery: a biopsychosocial perspective. J Occup Rehabil. 2013:23(4):536546.

15. Daud AZC, Yau MK, Barnett F, Judd J, Jones RE, Nawawi RFM. Integration of occupation based intervention in hand injury rehabilitation: a randomized controlled trial. J Hand Ther. 2016:29(1):30-40.

16. Grob M, Papadopulos NA, Zimmermann A, Biemer E, Kovacs L. The psychological impact of severe hand injury. J Hand Surg Eur. 2008:33:358-362.

17. Williams AE, Newman JT, Ozer K, Juarros A, Morgan SJ, Smith WR. Posttraumatic stress disorder and depression negatively impact general health status after hand injury. J Hand Surg Am. 2009:34(3):515-522.

18. Leventhal H, Meyer D, Narenz D. The common sense model of illness danger. In: Rachman S, eds. Medical Psychology Vol. 2. New York, NY: Pergamon: 2003:7-30.

19. Hagger MS, Orbell S. (2003). A meta-analytic review of the common sense model of illness representations. Psychol Health. 2003:18(2):141-184.

20. Rutter CL, Rutter DR. Illness representation, coping, and outcome in irritable bowel syndrome (IBS). Br J Health Psychol. 2002:7:377-391.

21. Heijmans $M$. The role of patients' illness representations in coping and functioning with Addison's disease. Br J Health Psychol. 1999:4:137-149.

22. Arran N, Craufurd D, Simpson J. Illness perceptions, coping styles and psychological distress in adults with Huntington's disease. Psychol Health Med. 2014:19(2):169-179.

23. Ashley A, Marti J, Jones H, Velikova G, Wright P. illness perceptions within 6 months of cancer diagnosis are an independent perspective predictor of health-related quality of life 15 months post-diagnosis. Psycho-Oncol. 2015:24:1463-70.

24. Foster NE, Bishop A, Thomas E, Main C, Horne R, Weinman J, Hay E. (2008). Illness perceptions of low back pain patient in primary care: what are they, do they change and are they associated with outcome? Pain. 2008:136(1-2):177-187.

25. Lee BO, Chaboyer W, Wallis M. Predictors of health-related quality of life 3 months after traumatic injury. J Nurs Scholarsh. 2008:40:83-90. 
26. Hurt CS, Burn DJ, Hindle J, Samuel M, Wilson K, Brown RG. Thinking positively about chronic illness: an exploration of optimism, illness perceptions and well-being in patients with Parkinson's disease. Br J Health Psychol. 2014:19(2):363-379.

27. Fournier M, de Ridder D, Bensing J. Optimism and adaptation to chronic disease: the role of optimism in relation to self-care options of type 1 diabetes mellitus, rheumatoid arthritis and multiple sclerosis. Br J Health Psychol. 2002:7(4):409-432.

28. Gustafsson M, Amilon A, Ahilstrom G. Trauma-related distress and mood disorders in the early stage of an acute traumatic hand injury. J Hand Surg Eur Vol. 2003:28:332-338.

29. Gustafsson M, Ahlstrom G. Problems experienced during the first year of an acute traumatic hand injury - a prospective study. J Clin Nurs. 2004:13:986-995.

30. Grunert BK, Devine CA, Matloub HS, Sanger JR, Yousif NJ, Anderson RC, Roell SM. Psychological adjustment following work-related hand injury: 18-month follow-up. Ann Plast Surg. 1992:29:537-542.

31. Ware JE, Snow KK, Kosinski M, Gandek B. SF-36 Health Survey: Manual and Interpretation Guide. Boston: The Health Institute, New England Medical Centre: 1993

32. Koestler AJ. Psychological perspective on hand injury and pain. J Hand Ther. 2010:23(2):199-210.

33. Moss-Morris R, Weinman J, Petrie KJ, Horne R, Cameron LD, Buick D. The Revised Illness Perception Questionnaire (IPQ-R). Psychol Health. 2002:17(1):1-16.

34. Sawicki GS, Sellers DE, Robinson WM. Associations between illness perceptions and health-related quality of life in adults with cystic fibrosis. J Psychosom Res. 2011:70:161-7.

35. Weiss DS, Marmar CR. The impact of event scale - revised. In: Wilson JP, Keane TM, editors. Assessing psychological trauma and PTSD. New York: Guilford Press: 1997:399_ 411.

36. Horowitz M, Wilner N, Alvarez W. Impact of Events Scale: a measure of subjective stress. Psychosom Med. 1979:41:209-218.

37. Beck JG, Grant DM, Read JP, Clapp JD, Coffey SF, Miller LM, Palyo SA. The Impact of Event Scale - Revised: Psychometric properties in a sample of motor vehicle accident survivors. J Anxiety Disord. 2008:22(2):187-198.

38. Kroenke k, Spitzer RL, Williams JB. The PHQ-9: validity of a brief depression severity measure. J Gen Intern Med. 2001:16(9):606-613. 
39. Cameron IM, Crawford JR, Lawton K, Reid IC. Psychometric comparison of PHQ-9 and HADS for measuring depression severity in primary care. Br J Gen Pract. 2008:58:32-36.

40. American Psychiatric Association. (2000). Diagnostic and statistical manual of mental disorders (4th ed., text rev.). Washington, DC: Author.

41. Carver CS. You want to measure coping but your protocol's too long: consider the Brief COPE. Int J Behav Med. 1997:4(1):92-100.

42. Yusoff N, Low WY, Yip CH. Reliability and validity of the Brief COPE Scale (English version) among women with breast cancer undergoing treatment of adjuvant chemotherapy: A Malaysian study. Med J Malaysia. 2010:65(1):41-44.

43. Cooper C, Katona C, Livingston G. validity and reliability of the Brief COPE in carers of people with dementia. J Nerv Ment Dis. 2008:196:838-843

44. Beaton DE, Wright JG, Katz JN, and the Upper Extremity Collaborative Group. Development of QuickDASH: Comparison of three item-reduction approaches. J Bone Joint Surg Am. 2005:87-A(5):1038-1046.

45. Hudak PL, Amadio PC, Bombadier C. Development of an upper extremity outcome measure: the DASH (disabilities of the arm, shoulder and hand). The Upper Extremity Collaborative Group (UECG). Am J Indus Med. 1996:29:602-608.

46. Angst F, Goldhahn J, Drerup S, Flury M, Schwyzer HK, Simmen BR. How sharp is the QuickDASH? A refined content and validity analysis of the short form of the disabilities of the shoulder, arm and hand questionnaire in the strata of symptoms and function and specific joint conditions. Qual Life Res. 2009:18(8):1043-51.

47. Kopjar B. The SF-36 health survey: a valid measure of changes in health status after injury. Inj Prev. 1996:2:135-139.

48. Cederlund RI, Ramel E, Rosberg H-E, Dahlin, LB. outcome and clinical changes in patients $3,6,12$ months after a severe hand injury - can sense of coherence be an indicator for rehabilitation focus? BMC Musculoskelet Disord. 2010:11:286-97.

49. Failde I, Ramos I. Validity and reliability of the SF-36 Health Survey Questionnaire in patients with coronary artery disease. J Clin Epidemiol. 2000:53:359-365.

50. Bindara RR, Dias JJ, Heras-Palau C, Amadio PC, Chung KC, Burke FD. Assessing outcome after hand surgery: the current state. J Hand Surg Br. 2003:28:289-94.

51. Stafford L, Berk M, Jackson HJ. Are illness perceptions about coronary artery disease predictive of depression and quality of life outcomes? J Psychosom Res. 2009:66:211-220. 
52. Milligan GW. An examination of the effect of six types of error perturbation on fifteen clustering algorithms. Psychometrika. 1980:45:325-342.

53. Clatworthy J, Hankins M, Buick D, Weinman J, Horne R. Cluster analysis in illness perception research: a Monte Carlo study to identify the most appropriate method. Psychol Health. 2007:22(2):123-142.

54. Dempster M, McCorry NK, Brennan E, Donnelly M, Murray LJ, Johnston BT. Do changes in illness perceptions predict changes in psychological distress among oesophageal cancer survivors? J Health Psychol. 2011:16(3):500-509.

55. Graham L, Dempster M, McCorry NK, Donnelly M, Johnston BT. Change in psychological distress in longer-term oesophageal cancer carers: are clusters of illness perception change a useful determinant? Psycho-Oncol. 2016:25:663-9.

56. Salander $\mathrm{P}$, Lilliehorn $\mathrm{S}$, Hamberg K, Kero A. The impact of breast cancer on living an everyday life 4.5-5 years post-diagnosis - a qualitative prospective study of 39 women. Acta Oncol. 2011:50:399-407.

57. Hayes SC. Acceptance and commitment therapy, relational frame theory, and the third wave of behavioural and cognitive therapies. Behav Ther. 2004:35(4):639-665.

58. McCracken LM, Vowles KE. Acceptance and commitment therapy and mindfulness for chronic pain: model, process, and progress. Am Psychol. 2014:69(2):178-187.

59. Gregg J, Callaghan GM, Hayes SC, Glenn-Lawson J. Improving diabetes self-management through Acceptance, Mindfulness, and Values: a randomised controlled trial. J Consult Clin Psychol. 2007:75(2):336-343.

60. Tang V, Poon WS, Kwan P. Mindfulness-based therapy for drug-resistant epilepsy. An assessor-blinded randomised trial. Neurology. 2015:85(13):100-1107.

61. Bach P, Hayes SC. The use of acceptance and commitment therapy to prevent the rehospitalization of psychotic patients: a randomised controlled trial. J Consult Clin Psychol. 2002:70(5):1129-1139.

62. Lundgren T, Dahl J, Yardi N, Melin L. Acceptance and commitment therapy and yoga for drug-refractory epilepsy: a randomised controlled trial. Epilepsy Behav. 2008:13:102-108.

63. Hann KEJ, McCracken LM. A systematic review of randomized controlled trials of Acceptance and Commitment Therapy for adults with chronic pain: outcome domains, design quality, and efficacy. J Contextual Behav Sci. 2014:3(4):217-227. 
64. Gustafsson M. Ten year follow-up of health and disability in people with acute traumatic hand injury: pain and cold sensitivity are long-standing problems. J Hand Surg Eur.2011:36(7):590-598.

65. The British Pain Society. Guidelines for Pain Management Programme for Adults: an evidence-based review prepared on behalf of the British Pain Society. 2013:Accessed from https://www.britishpainsociety.org/static/uploads/resources/files/pmp2013 main FINAL v6. pdf

66. Faul F, Erdfelder E, Buchner A, Lang A-G. Statistical power analyses using G*Power 3.1: Tests for correlation and regression analyses. Behav Res Methods. 2009;41:1149-1160.69.

67. Dogu B, Kuran B, Sirzai H, Sag S, Akkaya N, Sahin F. The relationship between hand function, depression, and the psychological impact of trauma in patients with traumatic hand injury. Int J Rehab Res. 2014;37(2):105-9.

68. van Laarhoven HW, Schilderman J, Bleijenberg G, et al. Coping, quality of life, depression, and hopelessness in cancer patients in a curative and palliative, end-of-life care setting. Cancer Nurs. 2011;34:302-14.

69. Teo I, Fingeret MC, Liu J, Chang DW. Coping and quality of life of patients following microsurgical treatment for breast cancer-related lymphedema. J Health Psychol. 2016;21(12):2983-2993. 